\title{
Kekambuhan pada Pasien Penyalahguna Narkotika, Psikotropika, Zat Adiktif (Napza) Pasca Rehabilitasi: Kebijakan dan Program Penanggulangan**
}

\author{
Relapse in Drugs, Psycotrospic, Adictive Abuse Post Rehabilitation: Policy and Prevention \\ Programs
}

\author{
Raharni*, Sri Idaiani, dan Nita Prihatini \\ Pusat Penelitian dan Pengembangan Sumber Daya dan Pelayanan Kesehatan, Badan Penelitian dan Pengembangan \\ Kesehatan, Kementerian Kesehatan RI, Jln. Percetakan Negara No. 29 Jakarta Pusat, DKI Jakarta, 10560, Indonesia. \\ *Korespondensi Penulis: raharnis@yahoo.com \\ ** Artikel ini pernah disajikan dalam Prosiding $4^{\text {th }}$ International Symposium on Health Research 2019
}

Submitted: 20-01-2020, Revised: 06-06-2020, Accepted: 19-08-2020

DOI: https://doi.org/10.22435/mpk.v30i2.2699

\begin{abstract}
Abstrak
Penyalahgunaan Narkotika, Psikotropika, dan Zat Adiktif (NAPZA) merupakan masalah di Indonesia yang salah satu akibatnya yaitu kekambuhan (relapse). Relapse merupakan suatu proses dimana seseorang telah dinyatakan abstinence (pulih) dan kembali menggunakan NAPZA. Angka relapse masih tinggi di beberapa negara. Pengguna NAPZA mengalami kekambuhan antara satu bulan sampai dengan satu tahun setelah keluar dari program pengobatan. Tujuan penelitian adalah untuk mengetahui kebijakan dan program yang terkait dengan penanggulangan relapse NAPZA di panti rehabilitasi. Desain penelitian berupa cross sectional dan studi kualitatif melalui round table discussion (RTD) dengan para pemangku kepentingan yaitu Badan Narkotika Nasional (BNN), Badan Pengawasan Obat dan Makanan (BPOM), Direktorat Pencegahan dan Pengendalian Masalah Kesehatan Jiwa dan NAPZA Kementerian Kesehatan, Rumah Sakit Ketergantungan Obat (RSKO), praktisi kejiwaan, dan relawan, serta konfirmasi ke panti rehabilitasi. Hasil penelitian yang diperoleh menunjukkan belum ada standar minimal nasional untuk penanganan relapse NAPZA. Definisi relapse yang beragam menyebabkan perbedaan angka relapse. Angka relapse di Direktorat Jiwa dan NAPZA Kementerian Kesehatan tahun 2018 yaitu 24,3\% sebagai angka kasar (data klaim). Angka relapse NAPZA di BNN sebelum adanya program pasca rehabilitasi yaitu $90 \%$ dan setelah ada program pasca rehabilitasi menjadi $30 \%$. Angka relapse di UPT Rumah Rehabilitasi dan Terapi NAPZA, Lido Bogor sekitar 7\%. Belum ada standar secara nasional sampai berapa kali seorang penyalahguna NAPZA dianggap sebagai korban atau masuk kategori tindakan pidana. Kesimpulan penelitian menunjukkan adanya egosentrisme di masing-masing kementerian/lembaga dalam melakukan kebijakan penanganan penyalahgunaan NAPZA. Kebijakan Kementerian Kesehatan lebih menekankan pada rehabilitasi medis, Kementerian Sosial menekankan pada rehabilitasi sosial, sedangkan kebijakan BNN lebih komprehensif meliputi rehabilitasi medis, rehabilitasi sosial, dan pasca rehabilitasi. Pengawasan narkotika, psikotropika, dan prekusor komprehensif dilakukan oleh BPOM, mulai dari hulu sampai hilir yaitu dari impor, produksi, penyaluran, penyerahan, dan penggunaan. Aadanya aplikasi E-NAPZA serta sanksi administratif dan pidana dapat mengurangi peredaran gelap dan penyalahgunaan NAPZA. Melalui Instruksi Presiden Republik Indonesia No. 6 Tahun 2018 tentang Rencana Aksi Nasional Pencegahan Pemberantasan Penyalahgunaan dan Peredaran NAPZA dan Prekusor (P4GN) di kementerian/lembaga diharapkan membantu menurunkan angka relapse NAPZA.
\end{abstract}

Kata Kunci: kekambuhan; penyalahgunaan NAPZA; rehabilitasi; kesehatan jiwa 


\begin{abstract}
Narcotics, Psychotropic, and Addictive Substance Abuse (NAPZA) is a problem in Indonesia, one of the consequences is relapse. Relapse is a process where someone has been declared abstinence (recovered) and returns to using drugs. Relapse rates also still high in some countries. Drug users experience a relapse between one month to one year after leaving the treatment program. The aim of this research was to find out the policies and programs related to handling of NAPZA relapse in rehabilitation centers. The study design was cross sectional with qualitative study by conducting round table discussion (RTD) with stakeholders from the National Narcotics Agency (BNN), Drug and Food Control Agency (BPOM), Directorate for Prevention and Control of Mental Health and Drug Problems Ministry of Health, Drug Addiction Hospital, psychiatric practioners, volunteers, and confirmation to the rehabilitation center. The results of study showed that there was no national minimum standard for handling NAPZA relapse. The various relapse definition caused differences in relapse rates. Relapse rate according to Directorate Mental Health and NAPZA of the Ministry of Health in 2018 was 24.3\% as rough figures (claim data). NAPZA relapse rates in the National Narcotics Agency, prior to the post rehabilitation program, was $90 \%$, and decreasing to $30 \%$ after conducting post-rehabilitation program. While relapse rate in Rehabilitation and Therapy House, Lido Bogor was around $7 \%$. There is no national standard for how many times a drug user is considered a victim or categorized as criminal action. In conclusion, there is Ministries/institutions of egocentrism in handling NAPZA relapse. Ministry of Health emphasizes medical rehabilitation, Ministry of Social emphasizes social rehabilitation, while BNN more comprehensively covering medical rehabilitation, social rehabilitation, and post rehabilitation. Narcotics, psychotropic, and comprehensive precursor control is carried out by the BPOM comprehensively, from imports, production, distribution, delivery and the use. The existence of E-NAPZA, administrative sanctions and criminal sanctions will reduce illicit trafficking and drug abuse. Indonesian Presidential Instruction No. 6 of 2018 concerning the National Action Plan for the Prevention of Eradication of drug abuse and Circulation (P4GN), in ministries/institutions is expected to decrease the number of NAPZA relapse.
\end{abstract}

Keywords: relapse; drug abuse; rehabilitation; mental health

\section{PENDAHULUAN}

Narkotika adalah zat atau obat yang berasal dari tanaman atau bukan tanaman, baik sintetis maupun semisintetis yang dapat menyebabkan penurunan atau perubahan kesadaran, hilangnya indra perasa, mengurangi sampai menghilangkan rasa nyeri, dan dapat menimbulkan ketergantungan. ${ }^{1}$ Penyalahgunaan Narkotika, Alkohol, Psikotropika, dan Zat Adiktif (NAPZA) bukan menjadi masalah baru di Indonesia. NAPZA di satu sisi merupakan obat atau bahan yang bermanfaat di bidang pengobatan atau pelayanan kesehatan dan pengembangan ilmu pengetahuan, tetapi di sisi lain dapat pula menimbulkan ketergantungan yang sangat merugikan apabila disalahgunakan atau digunakan tanpa pengendalian dan pengawasan yang ketat dan saksama. ${ }^{2}$

Dalam Rencana Pembangunan Jangka Menengah Nasional (RPJMN) disebutkan, salah satu sasaran RPJMN 2020-2024 adalah meningkatnya perlindungan sosial bagi seluruh penduduk dengan target indeks keberfungsian sosial korban penyalahgunaan NAPZA 0,34 pada tahun 2019 meningkat menjadi 0,41 pada tahun 2024. ${ }^{3}$ RPJMN tahun 2020-2024 adalah dokumen perencanaan pembangunan nasional untuk periode 5 (lima) tahun terhitung sejak tahun 2020 sampai dengan tahun 2024. RPJMN tahun 2020-2024 merupakan tahapan penting dari Rencana Pembangunan Jangka Panjang Nasional (RPJPN) 2005-2025 karena akan mempengaruhi 
pencapaian target pembangunan dalam RPJPN.

Sasaran RPJMN ini kemudian diuraikan salah satunya melalui pokok-pokok dan permasalahan Rencana Strategi (Renstra) Kementerian Kesehatan tahun 2020-2024. Paada saat penelitian, Renstra sudah tersusun namun masih dalam bentuk draf. Sehingga artikel ini masih mengacu pada Renstra Kementerian Kesehatan 2015-2019.

Berdasarkan Renstra Kementerian Kesehatan 2015-2019, salah satu sasarannya adalah pembinaan pelayanan kesehatan jiwa. Sasaran kegiatan ini adalah meningkatnya mutu dan akses pelayanan kesehatan jiwa dan NAPZA. Indikator pencapaian sasaran tersebut adalah: a) Persentase Fasilitas Pelayanan Kesehatan (fasyankes) Institusi Penerima Wajib Lapor, (IPWL) pecandu narkotika yang aktif sebesar $50 \%$, b) Jumlah kabupaten/kota yang memiliki puskesmas yang menyelenggarakan upaya kesehatan jiwa sebanyak 280 kabupaten/kota, c) Persentase rumah sakit umum rujukan regional yang menyelenggarakan pelayanan kesehatan jiwa/ psikiatri sebesar $60 \%{ }^{4}$

Maraknya penyalahgunaan NAPZA tidak hanya terjadi di kota-kota besar saja, tapi sudah sampai ke kota-kota kecil di seluruh wilayah Republik Indonesia, mulai dari masyarakat dengan tingkat sosial ekonomi menengah bawah sampai tingkat sosial ekonomi atas. Sektor kesehatan memegang peranan penting dalam upaya penanggulangan penyalahgunaan NAPZA, melalui upaya promotif, preventif, terapi, dan rehabilitasi. United Nations Office on Drugs and Crime (UNODC) sebagai badan dunia yang mengurusi masalah narkotika mencatat setidaknya ada 271 juta jiwa di seluruh dunia atau $5,5 \%$ dari jumlah populasi global, dengan rentang usia antara 15 sampai 64 tahun telah mengonsumsi narkoba di tahun $2017 .^{5}$

Dari hasil penelitian yang dilakukan BNN secara periodik setiap tiga tahun diinformasikan angka prevalensi terhadap narkotika mulai tahun 2011-2019 terjadi penurunan yang cukup signifikan. Pada tahun 2011 2,23\% atau sekitar
4,2 juta orang, tahun 2014 2,18\%, tahun 2017 $1,77 \%$ dan pada tahun 2019 1,80\%. Terjadi peningkatan pada tahun 2019 sebesar 0,03\%. ${ }^{6}$ Berdasarkan data gabungan BNN, Polri, serta Bea dan Cukai, sejumlah barang bukti narkoba yang disita sepanjang 2017 yakni shabu sebanyak 4,71 ton, ganja sebanyak 151,22 ton, ekstasi sebanyak 2.940.748 butir, dan 627,84 kilogram. ${ }^{7}$ Terdapat 739 zat narkotika jenis baru atau New Psychoactive Substance (NPS) yang dilaporkan oleh 106 negara dan teritorial sudah beredar di dunia. $^{5}$

Salah satu akibat penyalahgunaan NAPZA yaitu kekambuhan (relapse). Relapse NAPZA adalah penggunaan kembali NAPZA setelah sebuah periode abstinensia. Beberapa ahli menganggap yang digolongkan kekambuhan hanya mencakup kepada orang-orang yang telah menyelesaikan atau melengkapi rangkaian terapi formal dan kembali menggunakan NAPZA dengan pola yang serupa atau lebih buruk dari penggunaan sebelum abstinensia. ${ }^{8}$ Relapse pada penyalahgunaan NAPZA disebabkan karena adiksi adalah suatu penyakit yang bersifat kronis atau akut. Rehabilitasi bukanlah menjadi jaminan penyalaguna NAPZA akan sembuh dari ketergantungannya. Banyak pengguna yang meskipun telah menjalani program rehabilitasi di panti, belum bisa benar-benar meninggalkan NAPZA atau sembuh. Angka relapse juga masih tinggi di beberapa negara yaitu 33\% di Nepal, 55,8\% di Cina, $60 \%$ di Swiss, dan $60-90 \%$ di Bangladesh. Pengguna NAPZA mengalami kekambuhan antara satu bulan sampai satu tahun setelah keluar dari program pengobatan. ${ }^{9}$ Berdasarkan data BNN, angka relapse NAPZA di BNN sebelum adanya program pasca rehabilitasi yaitu $90 \%$, setelah ada program pasca rehabilitasi yaitu $30 \%$.

Menurut $\quad$ Raharni, ${ }^{10}$ proporsi penyalahgunaan NAPZA di kalangan siswa SMU Negeri di Kota Bekasi sebesar 16,8\%. Faktorfaktor yang secara bermakna berhubungan dengan terjadinya penyalahgunaan NAPZA di kalangan siswa SMU Negeri Kota Bekasi yaitu faktor individu yang terdiri dari karakteristik, 
jenis kelamin, umur, serta pengetahuan; faktor lingkungan dalam keluarga yaitu variabel komunikasi; serta faktor lingkungan di luar keluarga yaitu variabel pergaulan teman sebaya dan penggunaan waktu luang.

Chang ${ }^{11}$ melakukan penelitian terhadap 40 mantan pecandu heroin. Pasien diberikan perlakuan berupa teknik fMRI kondisi istirahat atau memindai dengan menggunakan sistem MRI seluruh tubuh. Setelah 12 bulan followup, 21 peserta diklasifikasikan sebagai kambuh (relapse) dan 19 sebagai non-relapse. Tidak ada perbedaan yang signifikan antara kambuh heroin dan yang tidak kambuh berdasar usia, pendidikan, jumlah rokok yang dihisap per hari, lamanya merokok, lamanya heroin penyalahgunaan dan dosis heroin/metadon harian/akumulasi. Dengan menggunakan teknik fMRI kondisi istirahat dan analisis for regional homogeneity (ReHo), terbukti bahwa kaudat kanan dapat berfungsi sebagai biomarker potensial untuk memprediksi terjadinya relapse terhadap heroin dan harapan untuk mengurangi risiko kekambuhan. Menurut Scott, ${ }^{12}$ selama beberapa dekade terakhir semakin banyak bukti menunjukkan bahwa sekelompok pengguna narkoba menderita kondisi yang lebih kronis, dimana mereka mengalami siklus kekambuhan, pemulihan pengobatan, penahanan, dan pemulihan, yang seringkali berlangsung beberapa tahun. Probabilitas transisi ke pemulihan terkait dengan tingkat keparahan, orientasi masalah, kemanjuran diri, keterlibatan swadaya, lingkungan pemulihan, dan jumlah perawatan yang diterima. Kecanduan merupakan kondisi kronis serta menunjukkan kebutuhan dan keefektifan pemantauan dan pemeriksaan pascapelepasan.

Tujuan penelitian ini adalah untuk mengetahui berbagai kebijakan dan program serta alternatif program penanggulangan relapse NAPZA di panti rehabilitasi. Diharapkan hasil penelitian menjadi masukan bagi pemerintah terkait kebijakan dan upaya program penanggulangan relapse NAPZA di panti rehabilitasi.

\section{METODE}

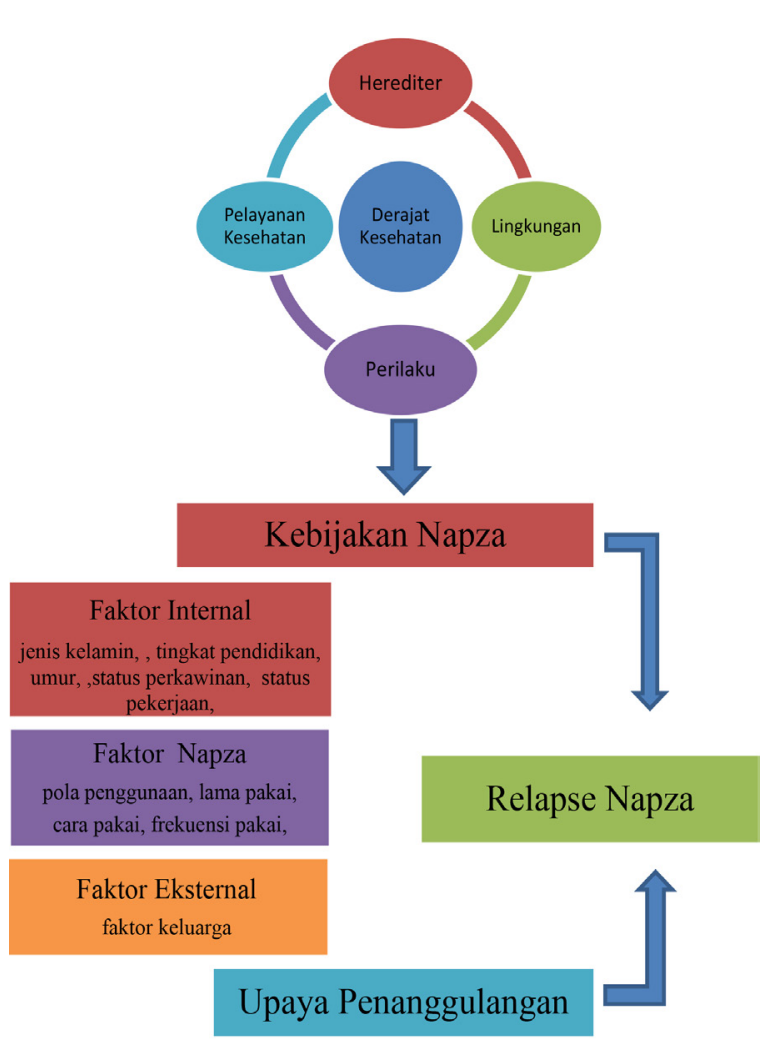

\section{Gambar 1. Kerangka Konsep Penelitian}

Desain penelitian adalah potong lintang (cross sectional), dengan pendekatan kualitatif. Pendekatan Kualitatif yaitu menyatakan secara tidak langsung atau mengungkapkan asumsi paradigma berdasarkan metodologi desain yang terus berubah berdasar pada pengalaman individu dalam latar ilmiah. ${ }^{13}$ Menurut Rubin dan Babbie, penelitian kualitatif adalah metode penelitian yang menekankan pada pengalaman manusia yang berusaha untuk mendapatkan arti lebih dalam mengembangkan teori yang ada. Gumilar mendefinisikan pendekatan kualitatif sebagai prosedur penelitian yang menghasilkan data deskriptif berupa kata-kata tertulis atau lisan dari orang orang dan perilaku yang diamati. Menurut mereka pendekatan dilakukan secara holistik. ${ }^{14}$

Subjek penelitian merupakan para pemangku kepentingan dan penentu kebijakan yang dipilih berdasar keterkaitan dalam penanganan relapse NAPZA yang terdiri dari BNN, BPOM, Direktorat Pencegahan dan 
Pengendalian (P2P) Masalah Kesehatan Jiwa Kementerian Kesehatan, RSKO, praktisi, dan relawan yang berkepentingan dalam program rehabilitasi penyalahguna NAPZA. Informasi terkait kebijakan dan program penanganan relapse NAPZA dilakukan dengan round table discussion (RTD) dari para pemangku kepentingan tersebut di atas. Selain itu dilakukan juga wawancara ke panti rehabilitasi NAPZA di Jakarta, Bogor, dan Bekasi pada bulan Mei-November 2018.

Teknik analisis dengan analisis data kualitatif dan dilakukan analisis konten, terkait dan upaya program terkait penanggulangan relapse. Hasil RTD dengan pemangku kepentingan di pusat dianalisis secara tematik untuk menghasilkan informasi kebijakan yang ada terkait relapse dan efektivitas program terkait penanggulangan relapse. Triangulasi data dari berbagai sumber data dilakukan dengan metode membandingkan informasi atau data secara berbeda. Untuk memperoleh kebenaran informasi yang handal dan gambaran yang utuh mengenai informasi tertentu, peneliti menggunakan informasi dari sumber yang berbeda untuk mengecek kebenaran informasi dengan mengundang beberapa narasumber yang berkepentingan dalam program rehabilitasi NAPZA, yaitu BNN, BPOM, Direktorat P2P Masalah Kesehatan Jiwa dan NAPZA Kementerian Kesehatan, RSKO, praktisi kejiwaan, dan relawan panti rehabilitasi.

\section{HASIL}

Hasil penelitian tantang kebijakan dan program penanggulangan kekambuhan pada penyalahguna napza, yang melibatkan berbagai stakeholder yaitu BNN, BPOM, Direktorat P2P MasalahKesehatan JiwadanNAPZAKementerian Kesehatan, RSKO, dan praktisi, diperoleh berbagai kebijakan penanggulangan kekambuhan penyalahgunaan NAPZA dari para stakeholder. Disamping itu juga diperoleh informasi terkait alternatif program penanggulangan kekambuhan pada penyalahguna NAPZA, seperti diuraikan di bawah.

\section{Kebijakan Penanggulangan Relapse Penyalahguna NAPZA}

Peraturan dan kebijakan yang terkait dengan penanggulangan relapse NAPZA terdiri dari peraturan perundang-undangan yang mengatur penanggulangan relapse NAPZA yaitu Undang-Undang Republik Indonesia No. 36 Tahun 2009 tentang Kesehatan, Undang-Undang Republik Indonesia No. 35 Tahun 2009 tentang Narkotik. Dalam pertauran tersebut diantaranya berisi: Pasal 127 tentang Narkotika mengatakan bahwa setiap penyalah guna narkotika golongan I bagi diri sendiri dipidana dengan pidana penjara paling lama 4 tahun. Kemudian, pengguna narkotika golongan II bagi diri sendiri dipidana dengan pidana penjara paling lama 2 tahun. Terakhir, pengguna narkotika golongan III bagi diri sendiri dipidana dengan pidana penjara paling lama 1 tahun. Jika penyalahguna narkoba terbukti hanya menjadi korban, maka individu terkait wajib menjalani rehabilitasi medis dan rehabilitasi sosial sesuai isi dari undangundang tersebut. Selanjutnya, Undang-Undang Republik Indonesia No. 5 Tahun 1997 tentang Psikotropika. Disamping itu, ada Peraturan Presiden tentang BPOM dan keputusan presiden tentang kedudukan, tugas, fungsi, kewenangan, susunan organisasi, dan tata kerja lembaga pemerintah non departemen. Selanjutnya ada 2 peraturan pemerintah dan 11 Peraturan Menteri Kesehatan, 5 Keputusan Menteri Kesehatan dan 1 Keputusan Kepala BPOM terkait narkotika dan psikotropika.

Hasil ini kemudian ditriangulasi dengan beberapa informan dan narasumber, yaitu dari BNN, BPOM, Direktorat P2P Masalah Kesehatan Jiwa dan NAPZA Kementerian Kesehatan, RSKO, praktisi kejiwaan serta relawan. Dari hasil RTD diperoleh bahwa kebijakan penanganan masalah penyalahgunaan NAPZA oleh Direktorat P2P Masalah Kesehatan Jiwa dan NAPZA Kementerian Kesehatan dilakukan pada tataran upaya pertama promotif-preventif. Strategi yang dilakukan adalah pencegahan 
primer meliputi peningkatan pemberdayaan orangtua, meningkatkan keterampilan tenaga kesehatan, meningkatkan pemberdayaan guru sekolah dasar dan sekolah menengah dalam pencegahan penyalahgunaan NAPZA, meningkatkan jumlah provinsi yang melakukan kampanye publik NAPZA yang melibatkan masyarakat, dan meningkatkan jumlah kader komunitas yang terlatih NAPZA. Sedangkan upaya sekunder dan tertier adalah meningkatkan jumlah institusi penerima wajib lapor yang aktif bagi penyalahguna NAPZA, meningkatkan jumlah provinsi yang memiliki institusi rehabilitasi NAPZA di luar sektor kesehatan yang bekerjasama dengan fasyankes, meningkatkan kerjasama dan sinergitas antara stakeholder.

Namun, untuk upaya kuratifdan rehabilitatif masih menjadi masalah, hal ini dikarenakan upaya penanggulangan penyalahgunaan NAPZA menjadi tugas Direktorat (P2P) Masalah Kesehatan Jiwa dan NAPZA, sementara tugas pokok dan fungsi dari P2P hanya pencegahan dan pengendalian. Oleh sebab itu, pada upaya kuratif dan rehabilitatif akan didorong untuk kembali ke Direktorat Jenderal Pelayanan Kesehatan (Ditjen Yankes), namun sejauh ini belum ada revisi permenkes untuk restrukturisasi kembali tugas tersebut. Selain itu menurut Badan Perencanaan Pembangunan Nasional (Bappenas), NAPZA merupakan prioritas nasional, diperlukan revisi permenkes untuk menjadi landasan kerjasama penanggulangan penyalahgunaan NAPZA antara Ditjen Yankes dan BNN.

Temuan lain didaptkan belum adanya standar minimal nasional dalam penanganan relapse NAPZA dan definisi relapse yang masih beragam dalam perhitungan angka relapse, sehingga terjadi perbedaan data angka relapse. Selain itu belum ada patokan secara nasional sampai berapa kali seorang penyalahguna NAPZA dianggap sebagai korban.

Dalam upaya pencegahan primer, Direktorat P2P Masalah Kesehatan Jiwa dan NAPZA mempunyai sistem informasi Sylaras sebagai sistem informasi IPWL yang menyediakan lembar konsultasi konseling, data fase pasien, namun sejauh ini tidak ada instansi yang menulis laporan. Konseling merupakan wawancara secara motivasional. Tujuan konseling pada kondisi relapse adalah membantu pasien untuk masuk ke lingkaran perubahan; eksplorasi makna dan kenyataan kekambuhan sebagai lesson learned; membantu klien mencari strategi alternatif pemecahan masalah; dan pertahankan kontak untuk dukungan. Data kekambuhan pasien yang pernah rehabilitasi berdasar Sylaras pada tahun 2018 adalah sejumlah 261 atau 24,3\% berdasar data klaim.

Direktorat P2P Masalah Kejiwaan dan NAPZA Kementerian Kesehatan menyatakan:

..."upaya kuratif dan rehabilitatif masih menjadi masalah karena masuk dalam P2P, sementara tugas pokok dan fungsi dari P2P hanya pencegahan dan pengendalian. Oleh sebab itu, pada upaya kuratif dan rehabilitatif akan di dorong untuk kembali ke Direktorat Pelayanan Kesehatan, namun sejauh ini belum diterima. Diperlukan revisi permenkes untuk mendorong kuratif dan rehabilitatif ke Ditjen Yankes.

..."Perhitungan angka kekambuhan berdasar sistem informasi Sylaras, hanya berdasar data klaim"...

Kebijakan BPOM dalam pengawasan narkotika, psikotropika, dan zat adiktif bertujuan untuk menjamin ketersediaan obat yang aman, berkhasiat dan bermutu; mencegah kebocoran dan penyimpangan (diversi) dari jalur legal ke jalur ilegal atau sebaliknya; dan mencegah terjadinya penyalahgunaan.

Pengawasan narkotika, psikotropika, dan prekursor farmasi untuk kepentingan pengobatan oleh BPOM meliputi: narkotika golongan II dan III; psikotropika golongan II, III, dan IV; dan prekursor farmasi meliputi Ephedrine, Pseudoephedrine, Norephedrine, Ergometrine, Ergotamine, dan Potassium Permanganat. Selain itu produk rumahan dan obat mengandung prekursor. 


\section{Alternatif Program Terkait dengan}

Penanggulangan Relapse NAPZA

Menurut BNN kebijakan rehabilitasi harus komprehensif dan berkelanjutan, berupa serangkaian upaya pemulihan terpadu terhadap pecandu, penyalahguna dan korban penyalahgunaan narkotika, yang mencakup penerimaan awal, rehabilitasi medis dan/atau rehabilitasi sosial dan dilanjutkan dengan layanan pasca-rehabilitasi, yang dilakukan secara terus menerus dalam suatu kesatuan layanan yang terintegrasi.

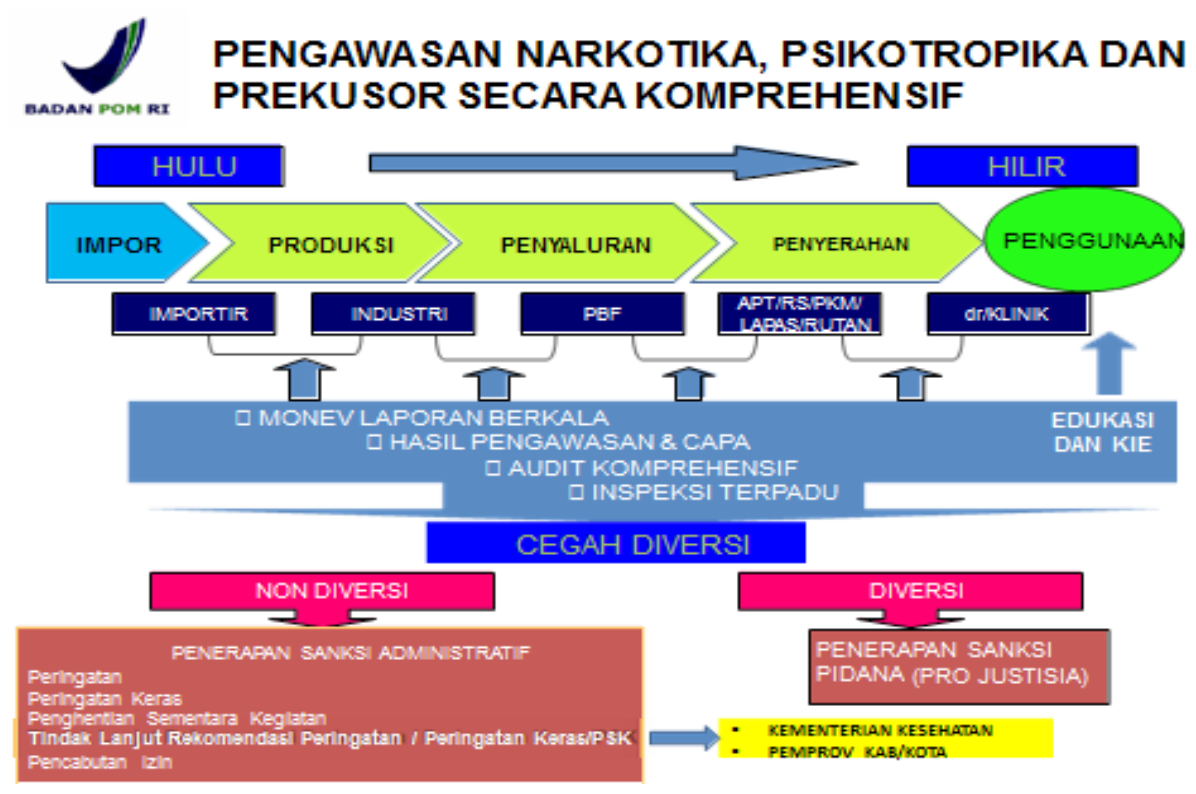

Gambar 2. Alur Pengawasan Narkotika, Psikotropika dan Prekusor (Sumber : BPOM 2018)

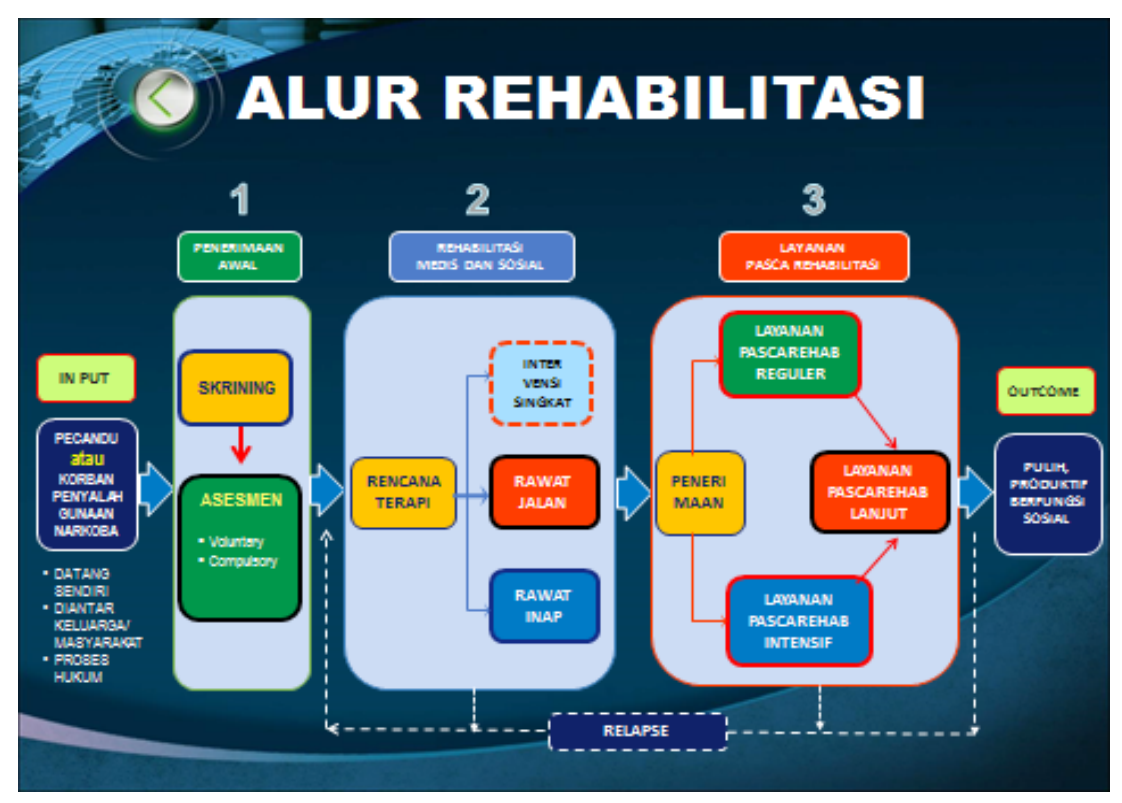

Gambar 3. Alur Rehabilitasi Penanggulangan Relapse Napza di BNN (Sumber : BNN 2018) 
Pada penerimaan awal dilakukan skrining dan pengkajian yaitu untuk mengidentifikasi apakah seseorang menggunakan/mengonsumsi narkoba atau tidak. Hal ini bertujuan untuk memilah apakah seseorang tersebut dalam keadaan adiksi/kecanduan sehingga memerlukan rehabilitasi atau tidak. Pada skrining ini dilakukan tes urine secara kualitatif dan pemeriksaan fisik dengan menggunakan instrumen singkat, cepat, valid, dan akuntabel.

Adapun pada tahap penilaian dilakukan pemeriksaan awal yang menyeluruh dan mendalam tentang kondisi dari klien terkait pemakaian narkoba dan dampaknya terhadap diri maupun lingkungannya. Hal ini dimaksudkan untuk mengetahui jenis zat dan tingkat keparahan serta dampak yang ditimbulkan secara fisik, kejiwaan, dan sosial akibat dari penggunaan narkoba. Pada tahap penilaian ini bertujuan untuk menetapkan rencana terapi - rehabilitasi yang akan diberikan (sesuai kebutuhan klien). Materi penilaian meliputi anamnesa identitas, riwayat pendidikan, pekerjaan dan dukungan hidup lainnya, riwayat penggunaan narkoba, riwayat keluarga dan lingkungan sosial, riwayat gangguan fisik/medis, masalah kejiwaan, keterlibatan dalam tindak kriminalitas, riwayat pelecehan, kekerasan fisik, seksual, pemeriksaan laboratorium penunjang, dan pemeriksaan ASI dan URICA.

\section{Menurut BNN:}

..." kebijakan rehabilitasi harus komprehensif dan berkelanjutan, adalah serangkaian upaya pemulihan terpadu terhadap pecandu, penyalahguna dan korban penyalahgunaan narkotika, yang mencakup penerimaan awal, rehabilitasi medis dan/ atau rehabilitasi sosial dan dilanjutkan dengan layanan pasca-rehabilitasi, yang dilakukan secara kontinu dlm suatu kesatuan layanan yang terintegrasi. Angka relapse NAPZA tinggi, karena masing-masing lembaga/kementerian melaksanakan tupoksi nya masing masing” ...
Kebijakan rehabilitasi yang komprehensif dan berkelanjutan merupakan serangkaian upaya pemulihan terpadu yang dilakukan oleh BNN meliputi rehabilitasi medis, rehabilitasi sosial, dan pasca rehabilitasi. Rehabilitasi medis adalah proses kegiatan pengobatan secara terpadu untuk membebaskan pecandu dari ketergantungan fisik terhadap narkoba. Bentuk kegiatan berupa detoksifikasi/terapi gejala putus obat, pemberian farmakoterapi dan psikoterapi, penanganan penyakit penyerta dan medicopsychiatric evaluation. Indikator keberhasilan rehabilitasi medis adalah hilangnya gejala putus obat (withdrawal syndrome), kondisi fisik, dan kejiwaan stabil, sehingga klien mampu menjalani semua rutinitas harian tanpa obat, adanya kesadaran kognitif klien terhadap bahaya dan dampak negatif penggunaan narkotika, test URICA: kontemplasi preparation.

Rehabilitasi sosial adalah kegiatan pemulihan terpadu, baik fisik, mental dan sosial agar mantan pecandu narkotika dapat kembali melaksanakan fungsi sosial dalam kehidupan masyarakat. Bentuk kegiatan berupa motivasi dan intervensi psiko-sosial, bimbingan mental spiritual dan bimbingan jasmani, bimbingan resosialisasi, pelatihan vokasional dasar dan kewirausahaan, perawatan dan pengasuhan bagi klien anak, perempuan dan disabilitas, dan evaluasi berkala dan rujukan. Pasca rehabilitasi merupakan tahap selanjutnya adalah program lanjutan yang diberikan kepada klien, yaitu mantan pecandu atau korban penyalahgunaan narkotika yang telah menyelesaikan rehabilitasi medis dan/atau rehabilitasi sosial, guna mempertahankan kepulihan (tidak kambuh). Merupakan bagian yang terintegrasi dan tidak terpisahkan dari rehabilitasi medis dan sosial, dalam upaya pemulihan ketergantungan narkotika. Diperlukan program pasca rehabilitasi karena adiksi merupakan penyakit kronis dan mudah kambuh (relapse). Penyebab kambuh adalah tidak mampu menghadapi trigger, tidak produktif/tidak memiliki pekerjaan, tidak mendapatkan dukungan sosial. Adapun alur rehabilitasi berkelanjutan dapat dilihat pada Gambar 4. 
Tujuan pasca rehabilitasi adalah membimbing klien agar mampu menghadapi trigger, yaitu situasi yang dapat menimbulkan terjadinya craving (keadaan nagih) dalam rangka mempertahankan kepulihan; memfasilitasi klien dalam mengembangkan minat, bakat, dan keterampilan sehingga mampu hidup produktif dan mandiri; mempersiapkan klien agar mampu menyatu kembali dalam lingkungan keluarga dan masyarakat serta berfungsi sosial.

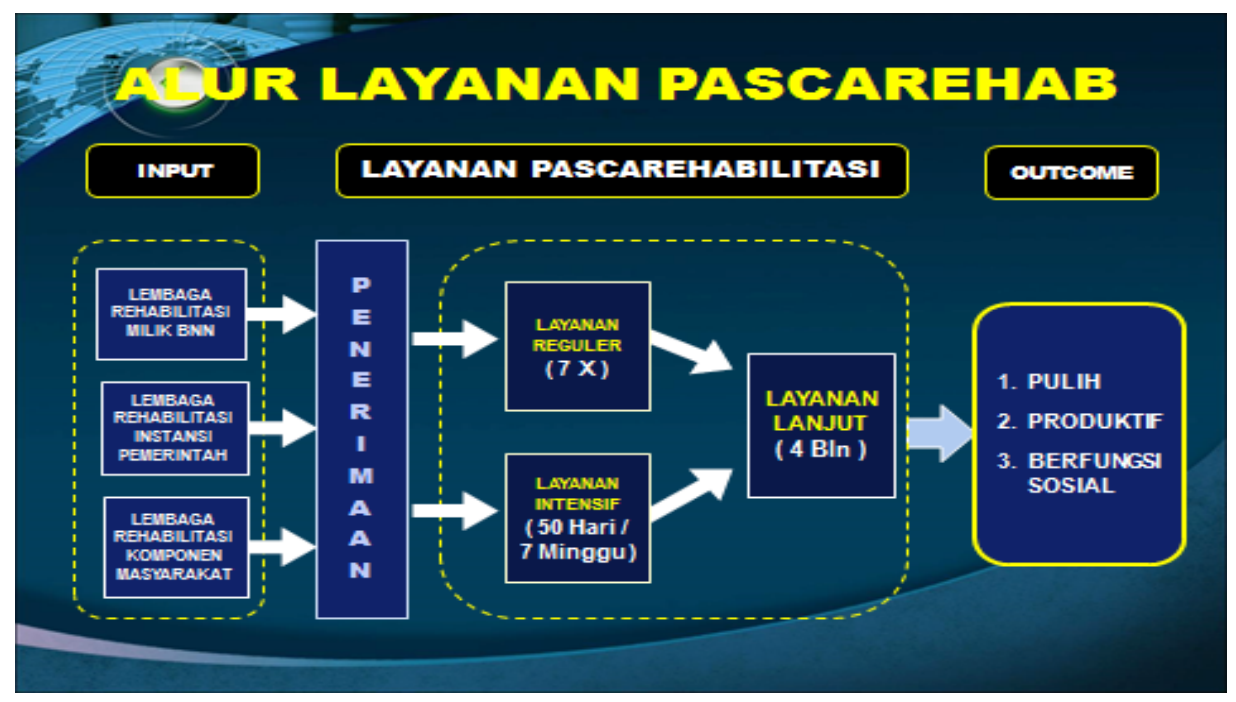

Gambar 4. Alur Layanan Pasca Rehab

(Sumber : BNN 2018)

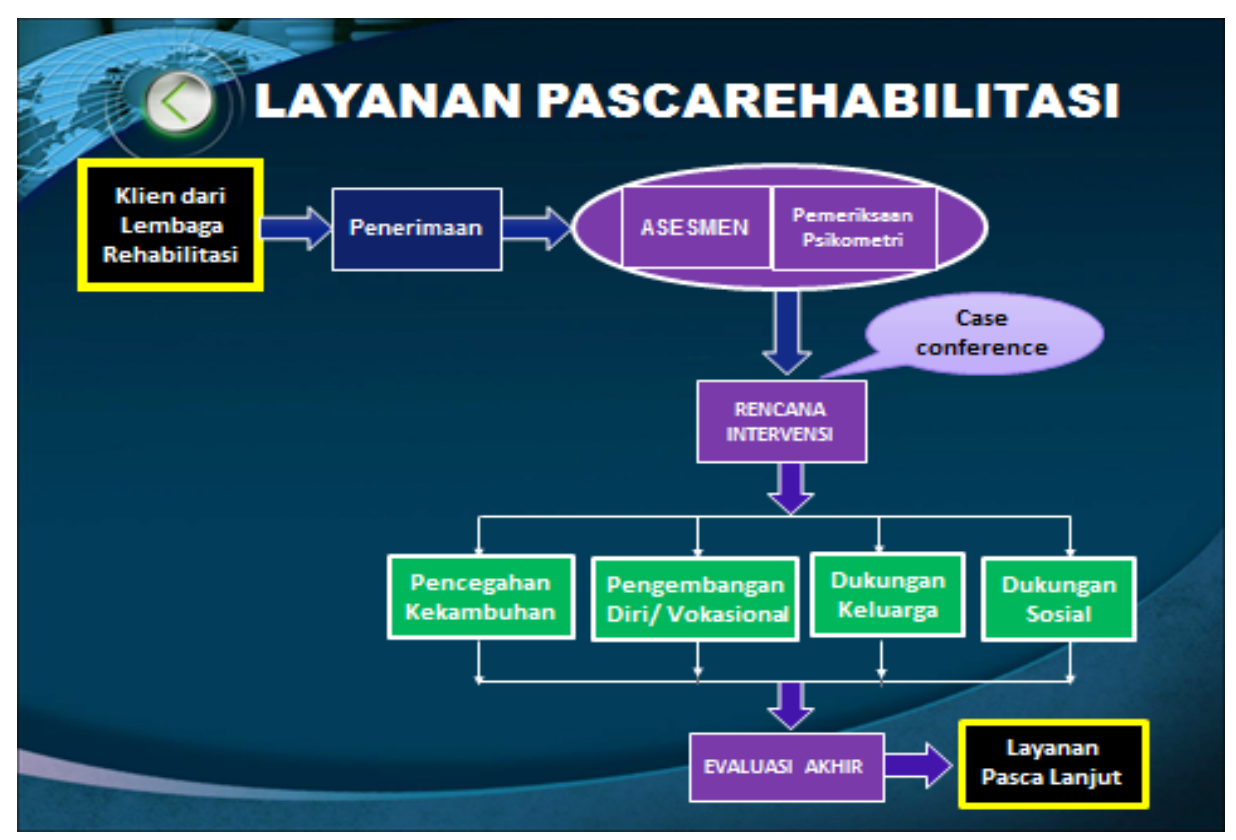

Gambar 5. Alur Layanan Pasca Rehabilitasi 


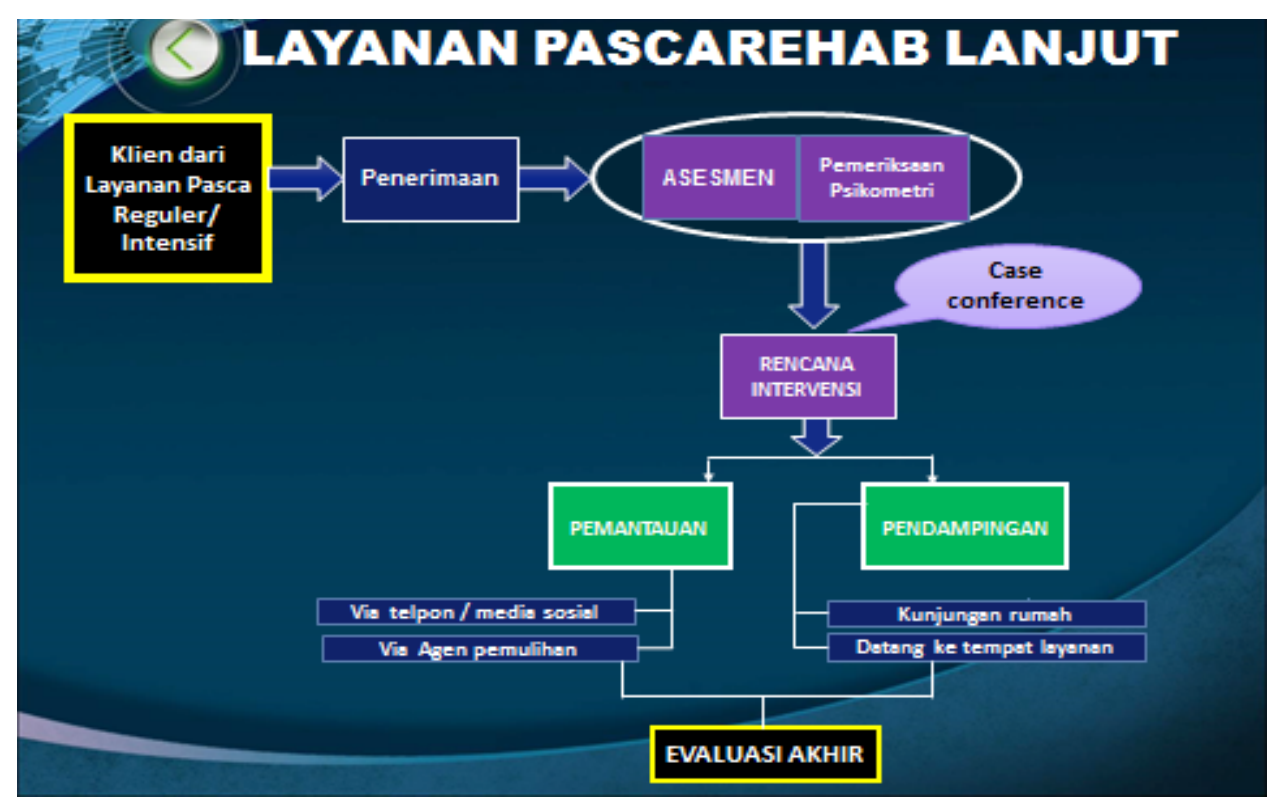

Gambar 6. Alur Layanan Pascarehab Lanjutan

(Sumber : BNN 2018)

Dari hasil penelitian diperoleh angka relapse NAPZA yang tinggi karena lembaga/ kementerian hanya melaksanakan tupoksinya masing-masing. Kementerian Kesehatan misalnya lebih menekankan intervensi medis saja, Kementerian Sosial lebih menekankan rehabilitasi sosial, sedangkan kondisi pasca rehab sangat menentukan terjadi atau tidaknya relapse. Klien yang telah mendapatkan hasil negatif pada saat tes urin, dinyatakan bersih, dan keluar dari rehabilitasi memiliki kemungkinan tinggi untuk bertemu NAPZA kembali, menggunakan lagi, dan akan relapse. Artinya sebenarnya klien yang direhabilitasi belum sembuh benar, sehingga tidak mampu menghadapi trigger.

Kebijakan BNN dalam melakukan rehabilitasi terhadap penyalahguna NAPZA bersifat komprehensif. Rehabilitasi dilakukan mulai dari pra-rehabilitasi sampai tahap rumah damping. Sesuai definisi rehabilitasi, pasien masuk dari awal kemudian melalui proses rehab medis, rehab sosial, dan dilanjutkan pasca rehab. Ini merupakan satu kesatuan alur rehabilitasi yang tidak terpisahkan. Rehabilitasi yang dilakukan Kementerian Kesehatan dan Kementerian Sosial dinilai kurang komprehensif. Rehabilitasi yang tidak dilakukan secara menyeluruh menyebabkan angka relapse yang tinggi mencapai 90\%. Data BNN menunjukkan bahwa dengan adanya program pasca rehab angka relapse kurang dari $30 \%$.

Indikator rehab adalah withdrawal selesai/ putus dan kondisi fisik medis stabil, yang dilanjutkan ke rehab sosial. Apabila klien telah telah selesai menjalani rehab medis dan/atau rehab sosial, maka seharusnya dikirim ke BNN yang mempunyai program pasca rehabilitasi.

Selanjutnyadiperlukan assessment sebelum klien mengikuti rehab, termasuk dampak rehab terhadap diri dan lingkungannya. Zat apa yang diminum, dampaknya bagaimana, secara sosial bagaimana dan pengaruhnya terhadap intervensi rehab yang akan dijalaninya. Individual plan, moving class, kelas konseling, intervensi korban perilaku, intervensi keluarga. Setelah melakukan assessment individual, baru kemudian masuk ke 
rehab medis dan rehab sosial.

Proses lepas dari ketergantungan fisik dilakukan dengan detoksifikasi, terapi putus obat. Proses dikatakan berhasil jika memenuhi 12 langkah, selanjutnya rehab sosial, kalau klien bisa beradaptasi, tidak pernah berbohong, pola pikir normal, baru tahap terminasi. Tidak ada kata sembuh dalam adiksi, namun pulih. Jika rehab berhenti sampai tahap ini saja, ada kemungkinan timbul relapse ketika klien kembali ke masyarakat. Oleh karena itu BNN menyediakan program pasca rehabilitasi enam bulan, diantaranya adalah pendampingan petugas. Pasca rehab adalah program lanjutan untuk mantan pecandu, karena kenyataannya banyak yang belum pulih setelah kembali dari program rehabilitasi. Kondisi klien sepulang dari rehabilitasi belum pulih sepenuhnya, masih ada kontemplasi. Klien yag benar-benar pulih akan mampu menolak jika ditawari untuk memakai NAPZA lagi. Pasca rehabilitasi dimaksudkan untuk mempertahankan kepulihan, karena secara teori kecanduan dinyatakan tidak bisa sembuh, namun yang ada adalah pulih.

Selama pecandu tidak produktif, muncul stigma atau anggapan sebagai sampah masyarakat sehingga belum bisa diterima dalam lingkungan. Di dunia international pecandu adalah korban. Peran program pasca rehab yaitu membantu pecandu setelah kembali ke masyarakat, membimbing masyarakat terhadap trigger, dan tetap dilakukan pemantauan/pendampingan. Klien diberikan penguatan lagi pada program pasca rehabilitasi dengan cara setting rawat inap ( 2 bulan), kemudian dinyatakan pulih karena tidak ada narkoba. Selanjutnya selama 4 bulan kembali ke masyarakat dilakukan pendampingan. Klien yang sudah melakukan rehab dan terapi di Lido dikembalikan ke keluarganya dan tetap menjalankan program pasca rehabilitasi karena kepulihan tidak bisa diukur setelah selesai di rehabilitasi di RS/panti saja.

BNN sudah melakukan pasca rehabilitasi, namun ada perdebatan, bahwa pasca rehabilitasi tidak wajib. Program pasca rehabilitasi pada dasarnya membantu klien untuk mengeliminer penyebab trigger. Kegiatan pasca rehabilitasi BNN antara lain berupa konseling, dinamika kelompok, simulasi, dan praktik lapangan. Contohnya jika klien mendapat NAPZA di diskotik, maka diajaklah ke tempat diskotik sampai bisa mengeliminir trigger.

\section{PEMBAHASAN}

Kebijakan dan program penanggulangan relapse pada penyalahguna NAPZA pasca rehabilitasi masih bersifat egosentrisme sesuai kebijakan masing-masing kementerian dan lembaga. Kementerian Kesehatan lebih menekankan pada rehabilitasi medis sedangkan Kementerian Sosial lebih menekankan pada rehabilitasi sosial. BNN melakukan program penanggulangan relapse NAPZA secara lebih komprehensif mulai dari rehabilitasi medis, rehabilitasi sosial, dan pasca rehabilitasi. Belum adanya standar minimal nasional dalam penanganan relapse penyalahguna NAPZA dan definisi relapse yang masih beragam dalam perhitungan menyebabkan terjadinya perbedaan data angka relapse. Diperlukan kejelasan definisi relapse yang sama dalam perhitungan angka relapse, dan standar minimal nasional dalam penanggulangan relapse penyalahguna NAPZA di kementerian/lembaga meskipun bukan berarti harus ada keseragaman program.

Perlunya pngembangan program untuk menekan kekambuhan yang berhubungan penyalahgunaan NAPZA di panti rehabilitasi NAPZA. Relapse NAPZA tinggi karena masingmasing lembaga/kementerian melaksanakan tupoksinya dengan egosentrisme. Kebijakan BNN dalam melakukan rehabilitasi terhadap penyalahguna NAPZA yang bersifat komprehensif, dilakukan mulai dari pra rehabilitasinya sampai tahap rumah damping. Rumah damping merupakan tempat pembekalan 
seusai (pecandu) menjalani masa pemulihan di balai rehabilitasi. Sesuai definisi rehabilitasi, pasien masuk dari awal, yaitu rehabilitasi medis, dan sosial, dilanjutkan pasca rehabilitasi, ini merupakan satu kesatuan yang tidak terpisahkan.

Menurut Handoyo P, dalam bukunya "War On Drugs: Refleksi Transformatif Penerapan Kebijakan Global Pemberantasan Narkoba di Indonesia", diusulkan agar pemerintah memberlakukan kebijakan diskriminalisasi dalam urusan penyalahgunaan narkoba, hal ini terkait besarnya anggaran kebijakan pemberantasan narkoba. Selain itu legalitas salah satu jenis narkoba ganja harus sudah mulai dipertimbangkan di Indonesia, mengingat saat ini sejumlah negara di Asia sudah melegalkan ganja untuk kepentingan negara. ${ }^{15}$

Malaysia menerapkan pendekatan yang komprehensif, seimbang dan holistik dalam upaya penanganan penyalahgunaan NAPZA dan memerangi narkoba. Seiring dengan kebijakan nasionalnya, upaya berkelanjutan Malaysia dalam memerangi narkoba juga dibuktikan dalam undang-undang nasionalnya yang menangani masalah narkoba dalam berbagai sudut pendekatan. National drug policy adalah kebijakan ekstensif yang menggabungkan pengurangan permintaan dan penawaran mendekati dan menggarisbawahi lima dorongan tindakan sebagai berikut: pendidikan preventif; perawatan dan rehabilitasi; penegakan hukum; pengurangan dampak buruk; dan kerjasama internasional. Semua komunitas bekerja secara kolektif dalam menemukan pendekatan yang adil dan komprehensif untuk mengatasi masalah terkait narkoba secara efektif. ${ }^{16}$

Thailand menambahkan poin pendekatan pengurangan dampak buruk dalam revisi kebijakan narkoba, salah satunya untuk mengurangi konsekuensi berbahaya dari suntikan obat sebagai upaya penaggulangan penyalahgunaan NAPZA. Pemerintah Thailand mengembangkan berbagai program yaitu layanan medis kecanduan, layanan kesehatan fisik dan mental, layanan sosial serta pendekatan holistik setelah layanan perawatan oleh para profesional kesehatan. Selain itu dilakukan pengembangan alternatif, yaitu implementasi kebijakan substansial dari Thailand dan memprioritaskan pendekatan yang dipimpin oleh manusia untuk menyelesaikan masalah-masalah budidaya opium dengan memperkenalkan alternatif mata pencaharian yang sah. Untuk beberapa dekade, pemerintah Thailand dan agen-agen mitranya telah bekerja dan mengimplementasikan pengembangan alternatif. Ruang lingkupnya tidak hanya di dalam negeri tetapi juga internasional untuk membantu penduduk desa memerangi tanaman terlarang. ${ }^{17}$

Jeffrey A. Miron dari Departement of Economic, Harvard University pernah meriset berapa pengeluaran pemerintah terkait kebijakan perang terhadap narkoba di Amerika Serikat pada Februari 2010 silam. Hasilnya dia tuangkan dalam The Budgetary Implication of Drug Prohibition (Implikasi Anggaran terkait Pelarangan Narkoba). Pasar bebas dalam obat-obatan dan kebijakan superior terhadap kebijakan larangan narkoba saat ini mungkin menjadi pengaruh tertinggi terhadap peningkatan substansial akan jumlah orang yang menggunakan narkoba dan mungkin juga mempengaruhi peningkatan yang signifikan dalam jumlah total obat yang dikonsumsi. Tetapi kebijakan itu akan menghasilkan pengurangan substansial akan efek berbahaya akibat penggunaan narkoba melalui pengurangan kekerasan, pengurangan kejahatan properti. $^{18}$

Instruksi Presiden Republik Indonesia Nomor 6 tahun 2018, tentang Rencana Aksi Nasional Pencegahan dan Pemberantasan Penyalahgunaan dan Peredaran Gelap Narkotika (P4GN) dan Prekusor Narkotika Tahun 20182019 mengintruksikan untuk melaksanakan rencana aksi nasional P4GN tahun 20182019 dan melaporkan hasil pelaksanaannya 
kepada Presiden melalui Kepala BNN setiap akhir tahun anggaran. ${ }^{19}$ Dalam melaksanakan rencana aksi P4GN, Kepala BNN melakukan koordinasi bersama kementerian dan lembaga dalam melaksanakan rencana aksi nasional P4GN tahun 2018-2019. Selain itu, kerjasama dilakukan dengan Menteri Dalam Negeri yang turut mengoordinasikan pemerintah daerah dalam melaksanakan rencana aksi nasional P4GN. Adapun pemantauan dan evaluasi rencana aksi nasional P4GN tahun 2018-2019 dilakukan bersama Menteri Perencanaan Pembangunan Nasional/Kepala Bappenas. Pelaksanaan rencana aksi nasional P4GN juga mengikutsertakan peran masyarakat dan pelaku usaha sesuai dengan ketentuan peraturan perundang undangan.

Aksi Nasional P4GN 2018-2019 yang dilakukan oleh beberapa bidang, antara lain: 1) Bidang Pencegahan yang meliputi kegiatan peningkatan kampanye publik tentang bahaya penyalahgunaan narkotika dan prekusor narkotika; deteksi dini penyalahgunaan narkotika dan prekusor narkotika; pengembangan pendidikan anti narkotika dan prekusor narkotika dan pemberdayaan masyarakat; 2) Bidang Pemberantasan, meliputi pembersihan tempat dan kawasan rawan peredaran gelap narkotika dan prekusor narkotika; penguatan pengawasan pintu masuk negara Republik Indonesia; pengembangan sistem interdiksi terpadu. ${ }^{20} 3$ ) Bidang Rehabilitasi meliputi peningkatan kapasitas rehabilitasi korban penyalahgunaan narkotika dan prekusor narkotika; peningkatan kapasitas layanan pasca rehabilitasi korban penyalahgunaan narkotika dan prekusor narkotika; 4) Bidang Penelitian dan Pengembangan Penanganan Penyalahgunaan Narkotika dan Prekusor Narkotika meliputi pengembangan riset permasalahan narkotika; dan prekusor narkotika dan integrasi data.

Pada tahun 2020-2024 Rencana Aksi Nasional P4GN difokuskan pada rehabilitasi dengan tujuan 1) peningkatan kapasitas dan aksesibilitas layanan rehabilitasi penyalahguna
NAPZA; 2) penyediaan layanan rehabilitasi yang responsif gender dan usia serta berbagai latar belakang pecandu, penyalahguna, dan korban penyalahguna NAPZA di setiap provinsi dan kabupaten/kota; 3) penyelenggaraan layanan rehabilitasi sesuai standar nasional rehabilitasi; dan 4) pengintergrasian sistem informasi rehabilitasi terpadu secara nasional.

Menurut Fitahayati, tingkat peran keluarga dalam mencegah terjadinya relapse tergolong rendah dan strategi yang harus dilakukan adalah optimalisasi pemberdayaan edukasi keluarga mengenai pentingnya peran keluarga untuk menjaga sistem keluarga dalam mendukung pemulihan kekambuhan terhadap residen yang berkesinambungan dan peningkatan fasilitas pendukung sistem pelayanan dan program sebagai strategi mencegah terjadinya relapse pada penyalahguna narkoba.

Ramadani menyatakan pentingnya dukungan sosial untuk menjaga proses pemulihan seperti dari lingkungan keluarga, teman, bahkan dari lingkungan tempat pasca rehabilitasi (instansi). Selain itu dibutuhkan keputusan pribadi untuk melanjutkan perawatan jika klien tidak ingin menggunakan narkoba, walaupun masih sangat sulit karena adanya berbagai pemicu seperti masalah keluarga, teman pecandu yang masih ada dan membuat klien relapse. ${ }^{21}$

Ketersediaan fasilitas yang mendukung dapat membantu klien untuk berubah, seperti adanya fasilitas program pembinaan keagamaan yang membuat mereka berfikir positif, dan fasilitas rumah damping yang sewaktu-waktu bisa digunakan. Dukungan lain dapat diperoleh dari keluarga, dengan cara lebih berhati-hati dalam bertindak dan berucap kepada klien agar tidak menimbulkan rasa kecewa terhadap keluarga, yang sewaktu-waktu membuat klien terpicu untuk menggunakan narkoba atau relapse. BNN juga harus lebih memperhatikan penyebaran informasi tentang program pasca rehabilitasi narkoba agar sampai di masyarakat. ${ }^{14}$ 
Di sisi lain, Kurniawan, Yuliawati, dan Hamdani pada penelitiannya yang dilakukan di Balai Rehabilitasi BNN Tanah Merah, Samarinda, menyimpulkan tidak ada perbedaan antara keluarga responden yang baik tetapi mengalami relapse yaitu sebanyak $18,9 \%$ dan untuk keadaan keluarga yang buruk serta mengalami relapse yaitu sebanyak $19,0 \%$. Secara statistik didapatkan dengan nilai $p$-value $1,00(p<0,05)$. Dalam penelitian itu disimpulkan bahwa tidak ada hubungan antara keadaan keluarga dengan perilaku relapse narkoba pada residen di Balai Rehabilitasi BNN Tanah Merah Samarinda. ${ }^{15}$

Menurut Atmadja, ${ }^{16}$ efektifitas program aftercare dalam upaya mengurangi bekas residen yang relapse sudah cukup efektif terbukti dengan adanya komunikasi dan hubungan kerja rumah damping terhadap masyarakat dan lembaga pemerintah/masyarakat sudah terlaksana dengan baik dan efektif. Sumber daya manusia (SDM) yang ada pun sudah cukup memenuhi dan memfasilitasi residen dalam mengikuti rangkaian kegiatan pasca rehabilitasi selama di rumah damping. Namun masih ada beberapa kendala yaitu belum adanya koordinasi yang baik antara pihak pelaksana dari tingkat pusat, provinsi, kabupaten/kota, juga terhadap orangtua bekas residen demi keberlangsungan pelaksanaan kegiatan yang effektif.

Temuan ini jelas mendukung kepercayaan yang tersebar luas bahwa kecanduan adalah kondisi kronis serta menunjukkan kebutuhan dan keefektifan pemantauan dan pemeriksaan pasca rehabilitasi. Metode dalam penelitian ini juga menyediakan metode yang sederhana namun dapat ditiru untuk mempelajari lebih lanjut tentang berbagai jalur yang dilalui individu sebelum mencapai kondisi jangka panjang pemulihan.

\section{KESIMPULAN}

Kebijakan dan program penanggulangan relapse pada penyalahguna NAPZA pasca rehabilitasi yang dilakukan kementerian/lembaga terkait dalam upaya penanganan kekambuhan relapse penyalahgunaan NAPZA masih bersifat egosentris sesuai dengan kebijakan masing-masing. Kementerian Kesehatan lebih menekankan pada rehabilitasi medis, Kementerian Sosial lebih menekankan pada rehabilitasi sosial. Kebijakan BNN dalam penanganan relapse NAPZA dilaksanakan dengan cara melakukan rehabilitasi secara lebih komprehensif mulai dari rehabilitasi medis, rehabilitasi sosial, dan layanan pasca rehabilitasi. Belum adanya standar minimal nasional dalam penanganan relapse NAPZA dan definisi relapse yang masih beragam dalam perhitungan angka relapse menyebabkan terjadi perbedaan data angka relapse. Belum ada patokan secara nasional sampai berapa kali seorang penyalahguna NAPZA dianggap sebagai korban. Pengawasan narkotika, psikotropika dan prekusor secara komprehensif dengan didukung penggunaan aplikasi E-NAPZA yang dilakukan oleh BPOM mulai dari hulu ke hilir yaitu dari impor, produksi, penyaluran, penyerahan dan penggunaan, serta adanya sanksi administratif dan pidana, dapat membantu mengurangi peredaran gelap NAPZA dan mengurangi penyalahgunaan NAPZA.

Adanya Intruksi Presiden Republik Indonesia No. 6 tahun 2018 tentang Rencana Aksi Nasional P4GN dan Prekusor Narkotika tahun 2018-2019 yang melibatkan semua kementerian/ lembaga dalam melakukan pengembangan berbagai program melalui Bidang Pencegahan, Bidang Pemberantasan, Bidang Rehabilitasi dan Bidang Penelitian dan Pengembangan terkait Prevalensi Penyalahgunaan NAPZA, diharapkan akan dapat mengurangi penyalahgunaan NAPZA dan menurunkan angka relapse NAPZA.

\section{SARAN}

Berdasar Inpres No 6 tahun 2018, perlu kiranya kementerian/lembaga untuk berkomitmen tinggi dan sepakat membuat suatu standar 
minimal nasional dalam upaya pencegahan kekambuhan (relapse) penyalahgunaan NAPZA yang komprehensif, sehingga meminimalkan egosentris dari masing masing kementerian/ lembaga. Selain itu perlu ditetapkan standar pencegahan relapse NAPZA yang komprehensif, meliputi rehab medis, rehab sosial dan pasca rehabilitasi dengan mempertimbangkan jenis NAPZA.

\section{UCAPAN TERIMA KASIH}

Ucapan terima kasih disampaikan kepada Kepala Pusat Sumber Daya dan Pelayanan Kesehatan, Badan Litbangkes atas dukungan dana untuk terlaksananya studi, BNN, BPOM, Direktorat Pencegahan dan Pengendalian Masalah Kesehatan Jiwa dan NAPZA, Kementerian Kesehatan, Rumah Sakit Ketergantungan Obat, Panti Rehabilitasi NAPZA di Jakarta, Bogor, dan Bekasi yang telah berpartisipasi dalam penelitian ini.

\section{DAFTAR PUSTAKA}

1. Republik Indonesia. Undang-Undang No. 35 Tahun 2009 tentang Narkotika. Jakarta; 2009

2. Republik Indonesia. Rencana Pembangunan Jangka Menengah Nasional 2015-2019. Jakarta; 2015

3. Republik Indonesia. Rencana Pembangunan Jangka Menengah Nasional 2020-2024. Jakarta; 2020.

4. Kementerian Kesehatan RI. Rencana Strategis Kementerian Kesehatan Tahun 2015 - 2019. Jakarta : Kementerian; 2015.

5. UNODC. United Nations Office on Drugs. Word Report UNODC. UNODC; 2017.

6. BNN. Press Release Akhir Tahun. Jakarta: BNN; 2019.

7. BNN. Survey Nasional Penyalahgunaan Narkoba. Jakarta : BNN; 2017.

8. Kementerian Kesehatan RI. Keputusan Menteri Kesehatan No. 422 tentang NAPZA - Pedoman
Penatalaksanaan Medik Gangguan Penggunaan NAPZA. Jakarta : Kemneterian Kesehatan ; 2010.

9. Maehira $Y$, et al. Factors Associated with Relapse into Drug Use among Male and Female Attendees of a Three-month Drug Detoxification - Rehabilitation Programme in Dhaka, Bangladesh : a Prospective Cohort Study. Harm Reduct. J. 2013;10(1):1.

10. Raharni. Faktor-faktor yang Berhubungan dengan Penyalahgunaan NAPZA pada siswa SMU Kota Bekasi. Jakarta; 2002.

11. Chang H, et al. Regional Homogeneity Changes Between Heroin Relapse and Non-Relapse Patients Under Methadone Maintenance Treatment: a Resting-state fMRI study. BMC Neurol. 2016:1-7.

12. Scott M. Dennis, Foss M. Utilizing Recovery Management Checkups to Shorten the Cycle of Relapse, Treatment Reentry, and Recovery. Drug Alcohol Depend. July 2005;78:325-338

13. Cropley A. Introduction to Qualitative Research Methods University of Hamburg. Hamburg; 2019.

14. Somantri GR. Memahami Metode Kualitatif. Makara Seri Sosial Humaniora. 2005;9(2), 57-65

15. Handoyo P. Wars on Drug. Jakarta; 2014

16. Ministry of Home Affairs Malaysia. Malaysia Country Report. Kuala Lumpur; Ministry of Home Affairs Malaysia; March 2019. pp. 12-15,

17. Office of the Narcotics Control Board (ONCB). "Thailand Country report. 2019 March, pp. 12$15,2019$.

18. Miron JA, Zwiebel J. The Economic Case Against Drug Prohibition. 1995;9(4): 175-192.

19. Republik Indonesia. Inpres Nomor 6 Tahun 2018 Rencana Aksi Nasional Pencegahan, Pemberantasan, Penyalahgunaan dan Peredaran Gelap Narkotika dan Prekusor 2018- 2019." Jakarta; 2018.

20. Republik Indonesia. Inpres No.2 Tahun 2020 Tentang Rencana Aksi Nasional P4GN-20202024. Jakarta; 2020. 
21. Ramadani S. Perilaku Pecandu Narkoba Pasca Rehabilitasi pada Badan Narkotika Nasional, Provinsi Sulawesi Selatan 2016 [Skripsi]. Makasar : UIN Alaudin; 2017.

22. Kurniawan D, Yuliawati R, Hamdani A. Hubungan antara Keadaan Keluarga dengan Perilaku Relapse (kekambuhan) Narkoba pada Residen. Nonember 2017; 7:93-98,.
23. Atmaja AS. Efektifitas Program Aftercare dalam Upaya mengurangi Eks Residen yang Relapse : Studi Kasus di Rumah Dampingan Jakarta. 2015. 